\title{
Tissue Doppler, strain, and strain rate echocardiography for the assessment of left and right systolic ventricular function
}

D Pellerin, R Sharma, P Elliott, C Veyrat

Heart 2003;89(Suppl III):iii9-iii 17

Tissue Doppler (TDE), strain, and strain rate echocardiography are emerging real time ultrasound techniques that provide a measure of wall motion. They offer an objective means to quantify global and regional left and right ventricular function and to improve the accuracy and reproducibility of conventional echocardiography studies. Radial and longitudinal ventricular function can be assessed by the analysis of myocardial wall velocity and displacement indices, or by the analysis of wall deformation using the rate of deformation of a myocardial segment (strain rate) and its deformation over time (strain). A quick and easy assessment of left ventricular ejection fraction is obtained by mitral annular velocity measurement during a routine study, especially in patients with poor endocardial definition or abnormal septal motion. Strain rate and strain are less affected by passive myocardial motion and tend to be uniform throughout the left ventricle in normal subjects. This paper reviews the underlying principles of TDE, strain, and strain rate echocardiography and discusses currently available quantification tools and clinical applications.

$\mathrm{F}$ or 30 years, the non-invasive ultrasonic assessment of myocardial function has relied on grey scale echocardiography and Doppler examination of intracardiac flow velocities. Technological advances in signal processing now make it possible to directly measure myocardial velocity and deformation in real time. Isaaz et al ${ }^{1}$ were the first to introduce the concept of tissue Doppler echocardiography (TDE) to assess myocardial velocity using the pulsed Doppler technique. The use of colour TDE was subsequently reported by Sutherland et $\mathrm{al}^{2}$ and Yamazaki et al. ${ }^{3}$ Heimdal et al introduced real time strain rate calculation in the longitudinal axis in $1998 .{ }^{4} \mathrm{TDE}$ is now available on most modern cardiac ultrasound systems and can be used during a routine echo examination to assess global and regional left ventricular function. The origin of TDE myocardial velocities is related to myocardial architecture and fibre orientation. This paper reviews the underlying principles of TDE, strain, and strain rate echocardiography and discusses currently available quantification tools and clinical applications.

\section{PRINCIPLES OF TISSUE DOPPLER ECHOCARDIOGRAPHY}

Unlike conventional Doppler signals that are typified by high velocity and low amplitude, myocardial motion is characterised by relatively low velocity and high amplitude signals. Tissue motion creates Doppler shifts that are approximately $40 \mathrm{~dB}$ higher than Doppler signals from blood flow whereas velocities rarely exceed $\pm 20 \mathrm{~cm} / \mathrm{s}^{1-3}$ To record low wall motion velocity, gain amplification is reduced and high pass filters are bypassed with the tissue signal directly entered into the autocorrelator.
During image acquisition, it is important to optimise the frame rate using an image sector as narrow as possible and to select the appropriate velocity scale. These parameters should be optimised at the time of imaging, as it is not possible to modify the frame rate and the velocity scale during postprocessing image analysis.

\section{MODALITIES OF TISSUE DOPPLER ECHOCARDIOGRAPHY}

TDE has three modalities: spectral pulsed wave Doppler, two dimensional, and M mode colour Doppler.

\section{Spectral Doppler}

Spectral pulsed TDE has the advantage of online measurements of velocities and time intervals and an excellent temporal resolution $(8 \mathrm{~ms})$. Figure 1 illustrates a normal TDE waveform. According to the Doppler principle, tissue velocities moving toward the transducer are positive, whereas velocities moving away from the transducer are negative. Since the wall moves whereas the sample volume is fixed, the spatial resolution is poor and myocardial layers cannot be separately analysed. The "onion bulb-like" shape of the sample volume also decreases lateral resolution.

\section{Colour Doppler}

In colour TDE, red encodes wall motion towards the transducer (positive velocities), whereas blue encodes wall motion away from the transducer (negative velocities). On each side of the scale, the brightest shades correspond to the highest velocities. Colour images require digital acquisition and storage for off-line post-processing analysis. In contrast to spectral Doppler, endocardial and epicardial layers can be separately analysed. Peak and mean velocities, time velocity integral, and regional time intervals can be measured in each myocardial segment, in each myocardial layer, and in each phase of the cardiac cycle.

$M$ mode colour encoded TDE has a high temporal resolution (5-10 ms). Colour two dimensional imaging has been limited by a slow frame rate, but parallel processing and advances in beam formation technology have increased the frame rate to a level adequate for analysis of most cardiac events (temporal resolution $10-100 \mathrm{~ms}$ ).

\section{QUANTIFICATION TOOLS FOR COLOUR TISSUE DOPPLER ECHOCARDIOGRAPHY RECORDINGS}

There are three TDE quantification tools currently available: reconstructed spectral pulsed wave TDE, curved $M$ mode colour display, and myocardial velocity gradient (MVG) analysis.

Abbreviations: AV, atrioventricular; MVG, myocardial velocity gradient; TDE, tissue Doppler echocardiography 


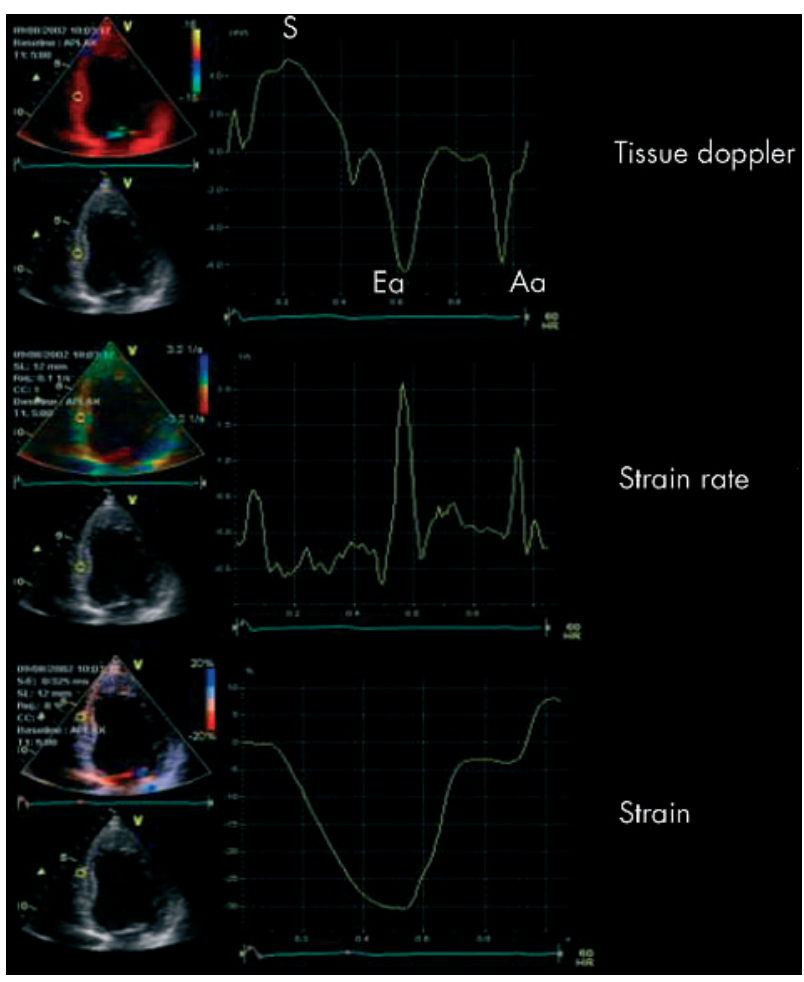

Figure 1 Tissue Doppler echocardiography (TDE), strain rate, and strain profiles of a normal subject obtained from an apical four chamber view. Time is on the horizontal axis. The region of interest is located in the mid inferoseptal segment. The TDE waveform consists of a first positive wave during the pre-ejection period, a systolic inward wall motion (S), followed by the isovolumic relaxation waves and by the outward wall motions Ea and Aa related to ventricular filling. Longitudinal strain rate profile is obtained from the same region of interest during the same cardiac cycle and shows corresponding waves. Negative systolic strain indicates longitudinal compression.

\section{Reconstructed spectral pulsed wave Doppler}

Simultaneous pulsed Doppler interrogation of multiple myocardial segments can be obtained off-line using high frame rate colour two dimensional TDE cine-loops in order to generate time-velocity plots. Velocities measured off line are lower than those obtained from online spectral pulsed TDE because they are derived from regional mean velocity rather than peak velocity. The major advantage of reconstructed spectral pulsed wave TDE is that information from several myocardial segments can be obtained within the same cardiac cycle.

\section{Curved M mode colour display}

The curved M mode colour velocity display is a reconstructed colour M mode recording along a manually traced line. Curved $M$ mode reconstruction provides an instantly interpretable visual display of segmental asynchrony between myocardial segments. Regional delays can be calculated according to temporal resolution (currently 10-20 ms), which depends on the frame rate.

\section{Myocardial velocity gradient}

In the normally contracting heart, the endocardium moves faster than the epicardium. The consequent velocity gradient across the thickness of the wall from the endocardium to the epicardium reflects the rate of change in wall thickness and is equivalent to strain rate. Systolic MVG is an indicator of regional myocardial contraction that is independent of the translational motion of the heart. MVG is also little affected by the Doppler angle of incidence. ${ }^{56}$ From the theoretical construct devised by Fleming in $1994,{ }^{7}$ a clinical method was proposed by several groups. ${ }^{8-17}$ MVG was defined as the slope of the regression line between myocardial velocities and wall thickness. Units are $\mathrm{s}^{-1}$. MVG can also be calculated as the difference between endocardial and epicardial velocities, divided by wall thickness. ${ }^{10}$ Another MVG calculation algorithm has been proposed ${ }^{17}$ using the time-velocity plot obtained by an automatic measurement of endocardial and epicardial velocities over time along a line parallel to endocardial or epicardial boundaries throughout the cardiac cycle. MVG calculations using this method correlate with that obtained by thickness-velocity plot and in addition provide automatic detection of peak velocity, timing, and duration of wall velocity changes over time.

TDE velocities have been validated using a rotating sponge model, ${ }^{8}$ ventriculography and digitised M mode echocardiography, ${ }^{1}$ myocardial length crystals, and high fidelity pressure and conductance catheters. ${ }^{18}$ A correlation has been shown between time intervals assessed by TDE and time intervals assessed haemodynamically. ${ }^{19}$ TDE velocities relate to the percentage of interstitial fibrosis and the myocardial $\beta$ adrenergic receptor density. ${ }^{20}$

\section{PRINCIPLES OF STRAIN AND STRAIN RATE ECHOCARDIOGRAPHY}

Strain and strain rate are TDE derived modalities that are now available in real time. Strain rate measures the rate of deformation of a tissue segment and is measured in $\mathrm{s}^{-1}$. Peak systolic strain rate represents the maximal rate of deformation in systole. An algorithm calculates spatial differences in tissue velocities between neighbouring samples within the myocardium aligned along the Doppler beam. A sample distance of 5-11 $\mathrm{mm}$ has been previously used. Strain is obtained by integrating strain rate over time and represents deformation of a tissue segment over time. Strain is expressed as the per cent change from the original dimension. Systolic strain represents the magnitude of deformation between end diastole used as a reference point and end systole (fig 1).

Systolic strain is positive and blue encoded when there is regional expansion. This is thickening in parasternal views and lengthening in apical views. Negative systolic strain is yellow-red encoded to denote regional compression, which is thinning in parasternal views and shortening in apical views. Infarcted myocardial tissue does not demonstrate shortening or lengthening activity and shows no or minimal systolic strain rate or strain, which is displayed as green. The technique of raw data storage and reconstruction permits the measurement of tissue velocity, peak systolic strain rate, peak early and late diastolic strain rate, and peak systolic strain from the same sample volume within the same cardiac cycle. Simultaneous interrogation of multiple myocardial segments and curved $\mathrm{M}$ mode colour display are also applicable to strain and strain rate.

Myocardial strain and strain rate have been validated in vitro using compressed gelatin phantoms ${ }^{2122}$ and in vivo using ultrasonic crystals, ${ }^{23}$ pressure-volume loops, ${ }^{24}$ or magnetic resonance imaging..$^{25}$ Peak posterior wall systolic strain rate accurately follows changes in myocardial contractility induced by adrenaline (epinephrine), $\beta$ blockers, and pacing. ${ }^{26}$

The inter-observer and intra-observer variabilities of TDE, strain, and strain rate measurements were less than $15 \%{ }^{27-30}$

\section{LIMITATIONS}

As with flow Doppler, TDE velocity, strain rate, and strain measurements are angle dependent. ${ }^{23} 31$ With the currently available technology, strain rate has a relatively poor signalto-noise ratio and is load sensitive. ${ }^{23}$ Strain measurements are 
made along a single ultrasound scan line. Three dimensional TDE may overcome this limitation. ${ }^{32}$ Limitations related to complex fibre architecture and to translation and rotation of the heart apply to all imaging modalities. Off-line analysis is required for colour images, which is time consuming.

\section{ASSESSMENT OF GLOBAL SYSTOLIC LEFT AND RIGHT VENTRICULAR FUNCTION}

TDE can be used to assess left ventricular ejection fraction using mitral annular velocity measurements during a routine study. This method is quicker and easier than the Simpson's rule with better reproducibility because tissue velocity assessment is not dependent on endocardial definition. Mitral annular velocity can be measured in more than 95\% of patients. ${ }^{33}{ }^{34}$ Heart contraction is caused by complex myocardial fibre architecture and orientation and has three components: longitudinal, radial, and rotational between base and apex.

\section{Long axis function}

Long axis function is assessed from the apical window. Harvey Feigenbaum suggested the assessment of mitral annular motion by echocardiography as an index of left ventricular systolic function in 1967 using M mode recordings. ${ }^{35}$ Velocities derived from the mitral annulus or the left ventricular base primarily reflect longitudinal motion. The longitudinally directed fibres are found in the subendocardium. ${ }^{36}{ }^{37}$ As the apex of the heart remains stationary, long axis changes are reflected in movements of the base.

Mitral annular systolic velocity can be used as an index of global ventricular function. ${ }^{34} 353839$ Several investigators have shown significant positive correlations between left ventricular ejection fraction and six-site average peak systolic mitral annular velocity. ${ }^{33} 34$ 40-42 When the patients were divided into two different groups with respect to an ejection fraction $\geqslant 0.50$ or $<0.50$, a cut-off mean systolic mitral annular velocity of $\geqslant 7.5 \mathrm{~cm} / \mathrm{s}$ had a sensitivity of $79 \%$ and a specificity of $88 \%$ in predicting a preserved global left ventricular systolic function. ${ }^{33}$ Peak mitral annular systolic velocity from the apical four chamber view (average from inferoseptal and lateral sites) correlated most closely with left ventricular ejection fraction as an individual view. ${ }^{34}$

Mitral annular peak systolic velocity is also a sensitive indicator of alterations in left ventricular contractility induced by low dose dobutamine infusion at 1, 2, 3, and $5 \mu \mathrm{g} / \mathrm{kg} / \mathrm{min}^{43}$ Mitral annular systolic velocity significantly increased with only $1 \mu \mathrm{g} / \mathrm{kg} / \mathrm{min}$ of dobutamine and further incremental increases occurred with each subsequent dose. A linear dose-response relation was demonstrated within this narrow dosage range. Routine measures of left ventricular ejection fraction by Simpson's rule did not detect increases until the $3 \mu \mathrm{g} / \mathrm{kg} / \mathrm{min}$ dose. Another report showed that mitral annular systolic velocity can detect abnormal systolic function in patients with heart failure and a normal ejection fraction (diastolic heart failure). ${ }^{44}$

However, mitral annular velocity measurement cannot be used in patients with severe mitral annular calcification, prosthetic ring or prosthetic mitral valve.

Recently, mitral annular velocity has been shown to be a powerful predictor of cardiac death over the next two years and provides significant incremental prognostic value compared with clinical information and mitral deceleration time of the $\mathrm{E}$ wave $<160 \mathrm{~ms}^{45}$

Tricuspid annular velocity can be used as an index of right ventricular function in patients with heart failure. ${ }^{46}$ There was a good correlation between systolic annular velocity and right ventricular ejection fraction assessed by radionuclide ventriculography. A systolic annular velocity $<11.5 \mathrm{~cm} / \mathrm{s}$ predicted right ventricular ejection fraction $<45 \%$ with a sensitivity of $90 \%$ and a specificity of $85 \%{ }^{46}$ Tricuspid annular velocity may also be another prognostic index in patients with dilated cardiomyopathy. ${ }^{47}$

Myocardial acceleration during isovolumic contraction has recently been validated in experiments as a novel noninvasive index of right and left ventricular contractile function. ${ }^{48} 49$

\section{Radial function}

Radial function is assessed from the parasternal window. Systolic MVG can be used to assess ventricular function in patients with paradoxical septal motion. In patients with atrial septal defect and paradoxical septal motion seen on conventional echo recordings, septal MVG fitted within the range of control subjects. ${ }^{50}$

Unlike conventional echo that does not show left ventricular wall motion during the pre-ejection period, TDE displays several colour strips within the walls representing wall motions with rapid changes in direction of motion. The velocity reversals had mirror signs in opposite walls, featuring successive inward and outward wall motions. In both walls, there was a simultaneous inward motion toward the left ventricular cavity centre. ${ }^{165}$ Pre-ejection period inward motion velocity in the posterior wall correlated linearly with left ventricular systolic function. ${ }^{16}$

\section{Aging}

Transmitral inflow velocity, systolic and diastolic TDE velocity measurements vary with age. In contrast, there was no correlation between increasing age and systolic MVG. ${ }^{10} 5253$ An inverse relation has also been shown between age and systolic velocity at peak dose dobutamine, in both men and women. ${ }^{54}$

\section{Relation between systole and diastole}

A relation between systole and diastole has been described in patients with dilated cardiomyopathy evaluated by TDE. ${ }^{55}$ TDE ejection and early diastole peak velocities have been measured in controls and patients with multi-vessel coronary artery disease and in patients with idiopathic dilated cardiomyopathy. TDE ejection velocities were strongly and positively correlated with early diastole velocities in the left ventricular posterior wall. Velocity increase from ejection to early diastole was $<25 \%$ in $78 \%$ of patients with ischaemic heart disease and might be useful in the non-invasive selection of patients with global severe left ventricular dysfunction and multi-vessel coronary artery disease..$^{56}$

\section{QUANTIFICATION OF REGIONAL WALL MOTION}

TDE, strain, and strain rate have the potential to objectively quantify regional ventricular wall motion using high frame rate and high resolution acquisition systems, and off-line analysis of digital images.

\section{Heterogeneity of ventricular wall motion in normal subjects}

Normal values of TDE velocities have been reported ${ }^{57} 58$ and regional differences in myocardial velocities have been described between individual wall segments using TDE. ${ }^{52} 58-60$

In the parasternal view, velocities are lower in the anteroseptal wall than in the posterior wall. ${ }^{5960}$ The translational motion of the heart in the chest during the cardiac cycle is anteriorly directed in systole and posteriorly directed in diastole. Velocities related to these components are superimposed on the intrinsic wall velocities, increasing velocity values at the posterior wall, and decreasing them in the septum. Systolic MVG was also lower in the anteroseptal 
wall $\left(1.69(0.53) \mathrm{s}^{-1}\right)$ than in the posterior wall $(3.28$ (0.67) $\left.\mathrm{s}^{-1}\right)$.

In the apical view, the longitudinal velocity decreases from base to apex..$^{58}{ }^{61}$ However, this may not represent intrinsic differences in tissue velocities, as this gradient was not seen when strain rate was measured by either echocardiography or magnetic resonance imaging. ${ }^{25}$ Rather, the difference is a function of the greater motion of the whole heart at the base compared with the mid and apical regions. In addition, apical segments cannot be assessed using TDE because of the limited movement of the apex and unfavourable angle of incidence of apical myocardial motion with respect to the transducer position. Strain and strain rate are much less affected by passive myocardial motion and tend to be uniform throughout the left ventricle in normal subjects. The finding of MVG in a myocardial segment distinguishes active motion from passive translation. ${ }^{62}$

Longitudinal strain was lower than radial strain in controls. Longitudinal systolic strain and strain rate were $-25(7) \%$ and $-1.9(0.7) \mathrm{s}^{-1}$ respectively, whereas radial systolic strain was $-57(11) \%$ and systolic strain rate was $-3.7(0.9) \mathrm{s}^{-1} .63$

Velocities at the lateral margin of the tricuspid annulus are higher than those of the lateral mitral annulus. ${ }^{64}$ In the right ventricle, longitudinal strain and strain rate were higher than in the left ventricle and were heterogeneous with maximal strain and strain rate in the mid free wall segment. ${ }^{63}$

\section{Ischaemic heart disease}

Contraction of the ventricle in the longitudinal axis is mainly caused by subendocardial fibres ${ }^{36}$ which are sensitive to ischaemia. ${ }^{37}{ }^{65}$ Experimental and clinical studies have shown that during acute ischaemia, myocardial peak systolic velocity and strain rate were notably reduced or reversed within 5 seconds after coronary occlusion and were delayed. In addition, there was positive velocity after the end of ejection. ${ }^{62966-68}$ Post-systolic shortening or thickening is a sensitive marker of ischaemia and can be easily recognised by high velocity, strain rate or strain occurring during the isovolumic relaxation period, often extending into the early filling period..$^{28}{ }^{67}$ Accurate timing of the aortic valve closure is crucial for recognition of post-systolic shortening. However, post-systolic shortening is a normal finding in healthy subjects occurring in approximately a third of myocardial segments and, thus, is not always a marker of disease. Pathologic post-systolic shortening has high magnitude with coexisting reduction in systolic strain and strain rate, and its peak occurred later than in control subjects ${ }^{71}$ (fig 2). Strain echocardiography has been shown to be a more sensitive technique than TDE for detecting regional ischaemic wall motion abnormalities during acute ischaemia. ${ }^{29}$ Analysis of myocardial TDE velocities cannot distinguish between persistent ischaemia and stunning. ${ }^{14}$ This can be achieved using MVG calculation across the thickness of the wall without dobutamine infusion. ${ }^{72}$ However, ischaemia and stunning can be distinguished using a dobutamine infusion. In the case of ischaemia, strain and strain rate decreased with post-systolic shortening ${ }^{28}$ in contrast with stunning. ${ }^{69}$ Reduction in radial systolic strain occurred earlier that the reduction in tissue velocities or visually estimated wall motion score. ${ }^{73}$

Myocardial strain rate and strain have the potential to discriminate acute from chronic ischaemia and myocardial infarction. ${ }^{23}$ Infarcted myocardium is characterised by significantly reduced systolic and diastolic velocities, deformation rates, and MVG and by the loss of the homogeneous distribution of systolic strain rate from apical to basal segments. ${ }^{27} 33$ 74-77 In the border zone, systolic velocity and MVG were lower than in normal segments when there was a large myocardial infarction. Reduced systolic longitudinal velocities have been found in ischaemic segments even if there was normal wall motion on visual assessment. ${ }^{76}$ Using MVG, it was possible to distinguish between transmural and non-transmural acute myocardial infarction after reperfusion therapy without inotropic stimulation. ${ }^{72}$

\section{Quantification of stress echocardiography Detection of ischaemia}

Although clinically useful in its present form, the main limitations of stress echocardiography interpretation are the subjective visual analysis of endocardial motion and wall thickening and the necessity of adequate training. In addition, the low temporal resolution typically used in clinical stress echocardiography does not always allow accurate detection of small differences in asynchrony. ${ }^{78}$ Myocardial velocity may provide a more objective correlate of ischaemia, reducing the expertise needed for interpreting stress echocardiography with improved reproducibility.

TDE criterion to detect stress induced ischaemia is a lack of increase in peak systolic velocity ${ }^{79}{ }^{80}$ (fig 2). Cut-off values for detection of ischaemia have been proposed..$^{81}$ These cut-off values were selected according to the lower 20th centiles of the velocity distribution in a normal population and gave diagnosis accuracy equivalent to expert interpretation in wall motion. In the MYDISE (myocardial Doppler in stress echo) study, ${ }^{54}$ cut-off values were selected from receiver operator curves and were higher. A cut-off value of $10.3 \mathrm{~cm} / \mathrm{s}$ for left anterior descending coronary artery disease, $10.8 \mathrm{~cm} / \mathrm{s}$ for circumflex coronary artery disease, and $12.8 \mathrm{~cm} / \mathrm{s}$ for right coronary artery disease were found in corresponding basal segments at peak stress.

Strain and strain rate may be superior to TDE velocity indices in the detection of induced ischaemia. ${ }^{82}$ Measurements of endocardial velocity and conventional wall motion analysis did not reliably distinguish between ischaemic and non-ischaemic segments. In contrast an increase in MVG greater than $2.6 \mathrm{~s}^{-1}$ has been observed in nonischaemic segments, whereas no ischaemic segment showed an increase in MVG greater than $1.5 \mathrm{~s}^{-1}$.

The amplitude and timing of deformation were compared with conventional stress echocardiography, perfusion scintigraphy, and coronary angiography. ${ }^{83}$ Post-systolic shortening was found in all ischaemic segments (fig 3 ). The ratio of postsystolic shortening to maximal segmental deformation was the best quantitative parameter to identify stress induced ischaemia and may be used as an objective marker of ischaemia during dobutamine stress echocardiography. Compared with conventional echocardiography, strain rate colour curved $\mathrm{M}$ mode analysis improved sensitivity and specificity from $81 \%$ and $82 \%$ to $86 \%$ and $90 \%$, respectively. ${ }^{83}$

Time interval measurements are not influenced by the angle of incident ultrasound beam. Time to onset of myocardial relaxation in strain rate $M$ mode display was delayed in ischaemic segments in patients with coronary artery disease. ${ }^{3084}$ During dobutamine stress echocardiography, time to onset of relaxation decreased in all nonischaemic segments, whereas this decrease was blunted in ischaemic segments. ${ }^{84} \mathrm{~A}$ change in time to onset of relaxation of $20 \%$ could identify new wall motion abnormalities with a sensitivity of $95 \%$ and a specificity of $75 \%$.

\section{Detection of viability}

Quantification of regional left ventricular function may reduce the expertise needed for interpretation and improve the reproducibility for the identification of myocardial viability in patients with chronic coronary artery disease and severe left ventricular dysfunction. 


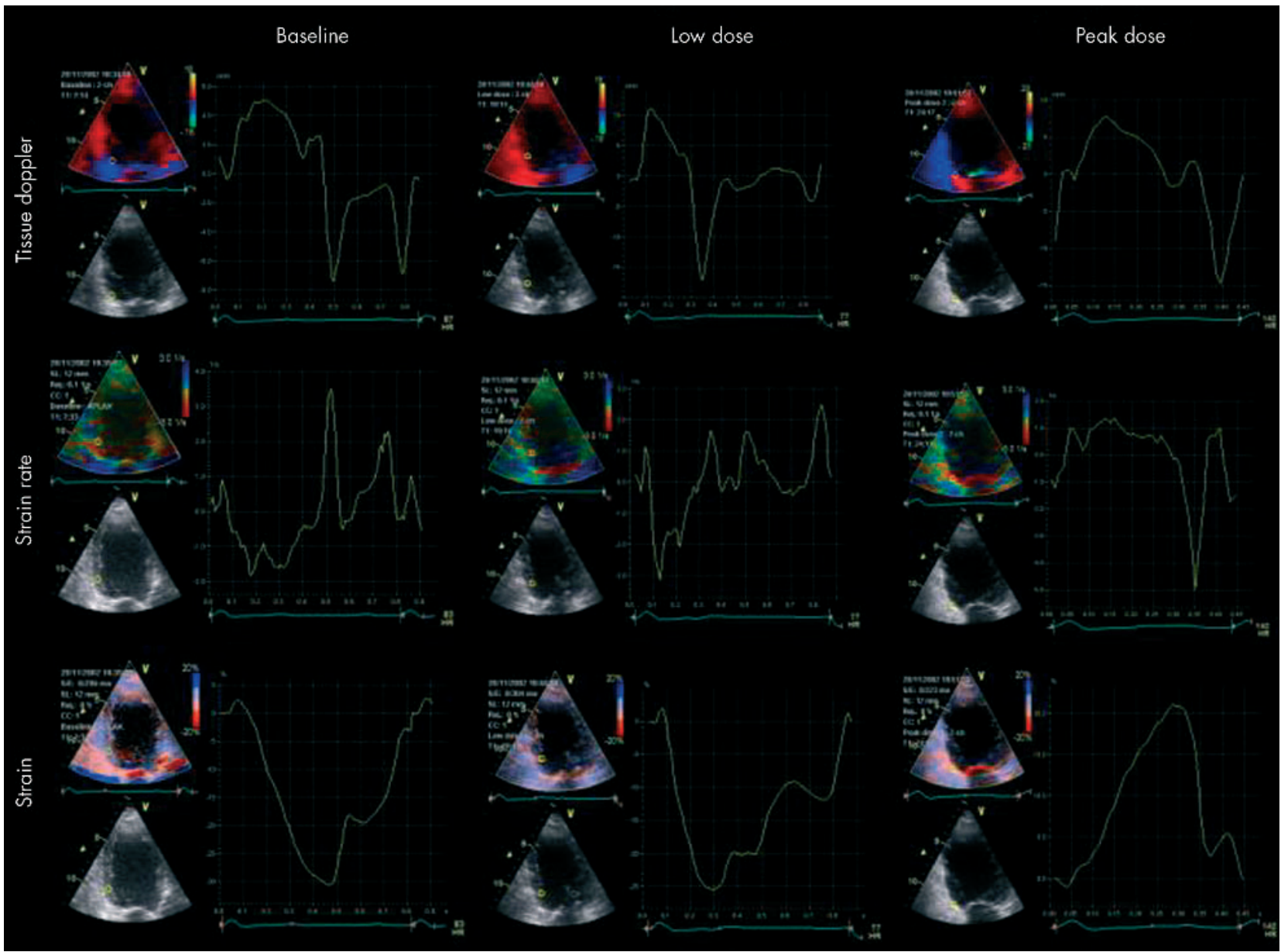

Figure 2 Quantitative analysis of a dobutamine stress echocardiographic study performed in a 53 year old patient who presented with atypical chest pain. Baseline, low dose, and peak dose dobutamine infusion have been recorded using colour high frame rate TDE. Strain rate and strain images were obtained and analysed off-line. The region of interest was located in the inferobasal segment where visual interpretation of changes in wall thickening and endocardial motion proved difficult. At baseline, longitudinal TDE, strain rate, and strain profiles showed a normal pattern with peak systolic velocity $5 \mathrm{~cm} / \mathrm{s}$, peak systolic strain rate $-1.9 \mathrm{~s}^{-1}$, and peak systolic strain $-30 \%$. During low dose dobutamine infusion, TDE velocity and deformation rate increased. Peak systolic TDE velocity was $11 \mathrm{~cm} / \mathrm{s}$ and peak systolic strain rate was $-3.1 \mathrm{~s}^{-1}$. In contrast, peak systolic strain mildly decreased to $-25 \%$. During peak dose dobutamine infusion, peak systolic TDE velocity was reduced to $7.8 \mathrm{~cm} / \mathrm{s}$. The basal inferior region showed longitudinal expansion in systole with inverted and positive peak systolic strain rate $+1.2 \mathrm{~s}^{-1}$ followed by pronounced negative strain rate during isovolumic relaxation (post-systolic shortening). Systolic strain was clearly positive as opposed to baseline and low dose dobutamine profiles. This segment, therefore, became ischaemic at peak stress and showed a biphasic response during incremental doses of dobutamine.

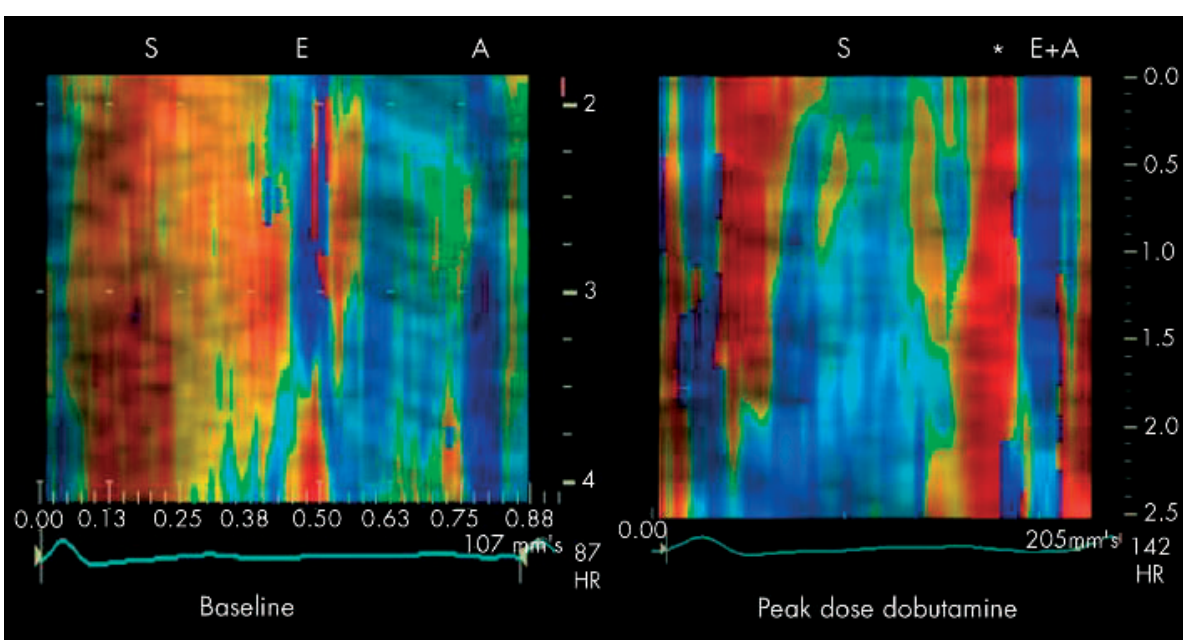

Figure 3 Colour curved $M$ mode longitudinal strain rate images in the same patient as in fig 2 obtained in the inferobasal segment at baseline and peak dose dobutamine infusion. At baseline, there is negative systolic strain rate (red encoded) showing normal longitudinal shortening. During peak dose dobutamine infusion, there is positive systolic strain rate (blue encoded) showing longitudinal expansion or lengthening. The systolic strip is followed by a red encoded strip ${ }^{*}$ ) occurring after aortic valve closure showing post-systolic shortening, another marker of ischaemia. Curved $M$ mode reconstruction provides a visual analysis of segmental deformation rate of myocardial segments. 
Sensitivity in the detection of viable myocardium was improved by using TDE velocity when compared with conventional echocardiographic parameters. ${ }^{85} 86$ A combination of echo and TDE techniques was able to detect as many severely hypokinetic or akinetic but viable segments as rest-reinjection thallium tomography in patients with chronic coronary artery disease and low left ventricular ejection fraction. ${ }^{87}$

In patients after myocardial infarction MVG between endocardium and epicardium during dobutamine stimulation showed high sensitivity for the prediction of reversible dysfunction. ${ }^{88}$ In patients with severe chronic three vessel disease and left ventricular dysfunction, transmural MVG could distinguish viable from non-viable segments when compared with rest-reinjection thallium tomography. ${ }^{89}$ In viable segments, the highest velocities were found in the mid layer conferring a bell shaped pattern to the MVG. Contractile reserve was mainly caused by increased mid wall velocities (fig 4). These results suggest that the contractile properties of diseased but viable myocardium are mainly concentrated in the mid layer. The dramatic ultrastructural changes observed in hibernating myocardium may explain the heterogeneity of the MVG. In non-viable segments, the distribution of velocity was close to zero or anarchic with small variation and did not change significantly with dobutamine. ${ }^{89}$

Changes in regional function of stunned myocardium during inotropic stimulation were better characterised by strain rate than by strain values on experiments. ${ }^{69}$

Using ${ }^{18} \mathrm{~F}$-fluorodeoxyglucose positron emission tomography as reference, an increase in systolic strain rate of $0.23 \mathrm{~s}^{-1}$ during low dose dobutamine infusion has been shown to discriminate viable from non-viable myocardium with a sensitivity of $83 \%$ and specificity of $84 \%$. In that study, strain echocardiography was superior to two dimensional or tissue Doppler imaging for the assessment of myocardial viability. ${ }^{90}$

\section{Cardiomyopathy}

Several studies have shown that TDE, strain, and strain rate echocardiography can detect subclinical dysfunction when conventional echocardiography is normal in patients with cardiomyopathy. One potential implication of this diagnostic sensitivity is the early detection of disease in asymptomatic gene carriers of familial cardiomyopathy.

Left ventricular hypertrophy is the clinical sign of familial hypertrophic cardiomyopathy and is absent in a significant number of subjects with causal mutations. In a transgenic rabbit model of human hypertrophic cardiomyopathy, TDE detected myocardial contraction and relaxation abnormalities, irrespective of cardiac hypertrophy. ${ }^{91}$ Mitral annular systolic and early diastolic velocities also detected myocardial abnormalities in patients with hypertrophic cardiomyopathy and provided early diagnosis before and independently of hypertrophy. ${ }^{92}$ Mitral annular systolic velocity $<12 \mathrm{~cm} / \mathrm{s}$ and early diastolic velocity $<13 \mathrm{~cm} / \mathrm{s}$ gave a sensitivity of $100 \%$ and a specificity of $90 \%$. This pioneer work has to be confirmed by other reports.

In patients with secondary left ventricular hypertrophy, radial function may compensate for longitudinal dysfunction. Normal short axis systolic function may be associated with abnormalities in the timing and amplitude of apically directed myocardial velocities in these patients. ${ }^{57}$

Distinguishing physiological adaptive left ventricular hypertrophy caused by exercise, as in athletes, from a pathological process, as in hypertrophic cardiomyopathy, despite similar left ventricular hypertrophy has been achieved in patients ${ }^{12}$ and in animal experiments ${ }^{93}$ using MVG across the thickness of the left ventricular posterior wall. MVG values $<7 \mathrm{~s}^{-1}$ showed a positive predictive value of $96 \%$ and a negative predictive value of $94 \% .^{12}$ This regional diastolic parameter was less sensitive in the older population. Long axis systolic and early diastolic velocities were decreased in patients with pathologic hypertrophy, but preserved in athletes. The best differentiation of pathologic from physiologic hypertrophy was provided by a mean systolic annular velocity $<9 \mathrm{~cm} / \mathrm{s}$ (sensitivity $87 \%$, specificity $97 \%$ ). ${ }^{94}$

In restrictive cardiomyopathy, mitral annular velocity and posterior wall MVG were reduced whereas these parameters were within normal range in constrictive pericarditis. ${ }^{95} 96$ MVG during isovolumic relaxation was positive in restrictive patients and negative in constrictive patients.

Cardiac AL (primary) amyloidosis is characterised by an early impairment in systolic function at a time when fractional shortening remains normal. This abnormality precedes the onset of congestive heart failure and can be detected by systolic strain and strain rate but is not apparent by TDE systolic velocity. ${ }^{97}$

Fabry cardiomyopathy is diagnosed by detection of left ventricular hypertrophy in patients with $\alpha$-galactosidase A deficiency. Conventional non-invasive tools are unable to provide a pre-clinical diagnosis allowing prompt institution of enzymatic therapy. Early detection of Fabry cardiomyopathy has been obtained by TDE before development of left ventricular hypertrophy. ${ }^{98}$

In patients with Friedrich's ataxia who were homozygous for the GAA expansion in the smaller allele of the Friedrich's ataxia gene, ${ }^{99}$ systolic and early diastolic radial MVG was lower than in age matched control subjects. A uniform reduction of strain and strain rate indices has also been
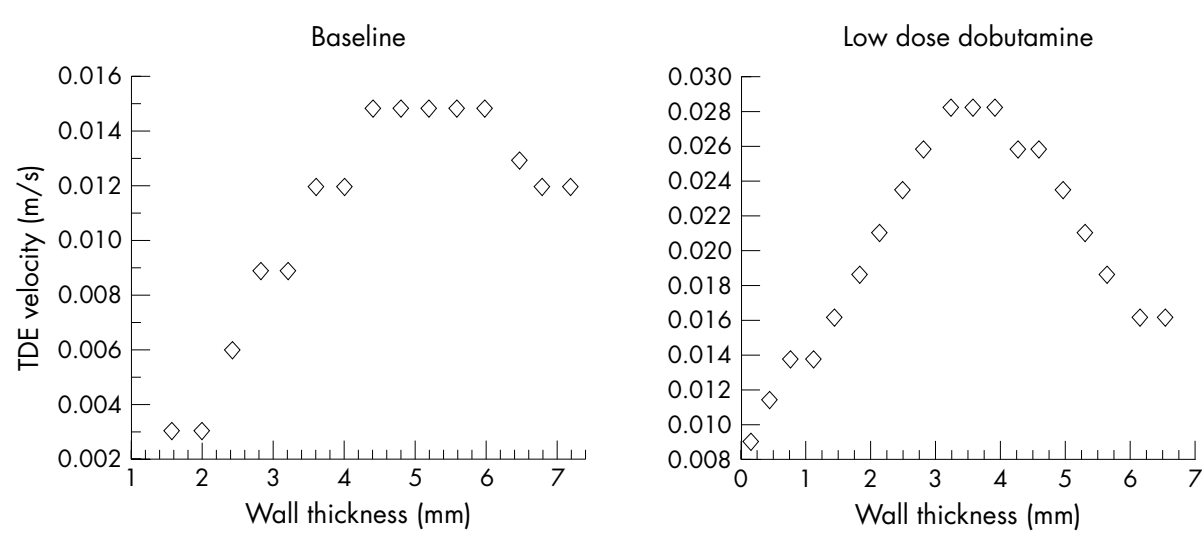

Wall thickness $(\mathrm{mm})$
Figure 4 Quantitative analysis of stress echocardiography for the detection of viable myocardium in a 63 year old man with severe three vessel coronary artery disease and a left ventricular ejection fraction of $32 \%$. Transmural myocardial velocities across the thickness of the wall were measured in a severely hypokinetic but viable segment assessed by echocardiography and rest-reinjection thallium tomography. The highest velocities were located in the mid layer conferring a bell shaped pattern to the myocardial velocity gradient in contrast with the

7 usual pattern of linearly decreasing velocity from endocardium to epicardium. During low dose dobutamine infusion contractile reserve was mainly caused by increased mid wall velocity. 
shown in hypertrophic and non-hypertrophic left ventricular myocardium in patients with Friedrich's ataxia whereas no changes occurred in the right ventricle. ${ }^{100}$

In patients with dilated cardiomyopathy, intraventricular mechanical asynchrony can be assessed by analysing the temporal relation of myocardial velocities between various segments of ventricular walls. The prevalence of left ventricular systolic and diastolic asynchrony was 51\% and $46 \%$, respectively, in patients with narrow QRS complexes, and $73 \%$ and $69 \%$, respectively, in patients with wide QRS complexes. ${ }^{101}$ As QRS complex duration is not a determinant of systolic asynchrony, intraventricular synchronicity has to be assessed by TDE when considering cardiac resynchronisation therapy. Detection of the most delayed left ventricular wall may guide left ventricular lead implantation and could be detected by the assessment of time to peak systolic velocity $^{102}$ and interval between the end of the A wave and beginning of the next E wave using DTE ${ }^{103}$ in basal segments.

\section{Multisite pacing}

After device implantation, several atrioventricular (AV) intervals are tested to optimally programme the device. The optimal AV delay is chosen as the shortest AV interval to obtain the longest left ventricular filling time without interruption of the A wave. ${ }^{104}$ Improvement of asynchrony, duration of left ventricular filling, duration of ejection as well as mitral regurgitation, and left ventricular remodelling are assessed. ${ }^{105}$

\section{CONCLUSION}

Tissue Doppler, strain, and strain rate echocardiography provides additional information to conventional echocardiography. A quick and easy assessment of left ventricular ejection fraction is obtained by mitral annular velocity measurement during a routine study, especially in patients with poor endocardial definition or abnormal septal motion. Tissue Doppler, strain, and strain rate echocardiography provides quantification of regional wall motion at rest and during stress. However, time consuming off-line analysis of colour images is required in the present state of technology.

Strain rate and strain are less affected by passive myocardial motion and tend to be uniform throughout the left ventricle in normal subjects.

These non-invasive techniques are rapidly evolving and expanding. Further refinements in signal processing and quantitative analysis are likely in the near future.

\section{ACKNOWLEDGEMENTS}

The authors would like to thank Mrs Harriet St Pierre for her technical assistance.

\section{Authors' affiliations \\ D Pellerin, R Sharma, P Elliott, The Heart Hospital, London, UK C Veyrat, Institut Mutualiste Monsouris, Paris, France}

Correspondence to: Dr Denis Pellerin, The Heart Hospital, 16-18 Westmoreland Street, London WIG 8PH, UK; denis.pellerin@uclh.nhs.uk

\section{REFERENCES}

1 Isaaz K, Thompson A, Ethevenot G, et al. Doppler echocardiographic measurements of flow velocity motion of left ventricular posterior wall. Am J Cardiol 1989;64:66-75

2 Sutherland GR, Stewart MJ, Groundstroem WE, et al. Color Doppler myocardial imaging: a new technique for the assessment of myocardial function. J Am Soc Echocardiogr 1994:7:441-58.

3 Yamazaki N, Mine Y, Sano A, et al. Analysis of ventricular wall motion using color-coded tissue Doppler imaging system. Jpn J Appl Phys 1994;33:3141-6.

4 Heimdal A, Stoylen A, Torp $\mathrm{H}$, et al. Real-time strain rate imaging of the left ventricle by ultrasound. J Am Soc Echocardiogr 1998;11:1013-9.
5 Donovan CL, Armstrong WF, Bach DS. Quantitative Doppler tissue imaging of the left ventricular myocardium: validation in normal subjects. Am Heart $J$ 1995; 130:100-4.

6 Bach DS, Armstrong WF, Donovan CL, et al. Quantitative Doppler tissue imaging for assessment of regional myocardial velocities during transient ischemia and reperfusion. Am Heart $J$ 1996;132:721-5.

7 Fleming $A D, X i a X, M c D i c k e n W N$, et al. Myocardial velocity gradients detected by Doppler imaging. Br J Radiol 1994;67:679-88.

8 Miyatake K, Yamagishi M, Tanaka N, et al. New method for evaluating left ventricular wall motion by color-coded tissue Doppler imaging: in vitro and in vivo studies. J Am Coll Cardiol 1995;25:717-24.

9 Uematsu M, Miyatake K, Tanaka N, et al. Myocardial velocity gradient as a new indicator of regional left ventricular contraction: detection by a twodimensional tissue Doppler imaging technique. J Am Coll Cardiol 1995;26:217-23

10 Palka $\mathbf{P}$, Lange A, Fleming $A D$, et al. Age-related transmural peak mean velocities and peak velocity gradients by Doppler myocardial imaging in normal subjects. Eur Heart J 1996;17:940-50.

11 Palka P, Lange A, Wright RA, et al. Myocardial velocity gradient measured throughout the cardiac cycle in dilated cardiomyopathic hearts. A potential new parameter of systolic and diastolic myocardial function by Doppler myocardial imaging. Eur J Ultrasound 1997;5:151-4.

12 Palka $P$, Lange A, Fleming $A D$, et al. Differences in myocardial velocity gradient measured throughout the cardiac cycle in patients with hypertrophic cardiomyopathy, athletes and patients with left ventricular hypertrophy due to hypertension. J Am Coll Cardiol 1997;30:760-8.

13 Derumeaux G, Cochonneau O, Douillet R, et al. [Comparison of myocardial velocities by tissue color Doppler imaging in normal subjects and in dilated cardiomyopathy]. Arch Mal Coeur Vaiss 1997;90:773-8.

14 Derumeaux G, Ovize M, Loufoua J, et al. Assessment of nonuniformity of transmural myocardial velocities by color-coded tissue Doppler imaging: characterization of normal, ischemic, and stunned myocardium. Circulation 2000;101:1390-5.

15 Cohen L, Pajany F, Pellerin D, et al. Cardiac wall tracking using Doppler tissue imaging. International Electronic and Electrical Engineering (IEEE) Transactions on Pattern Analysis and Machine Intelligence 1996;3:295-8.

16 Pellerin D, Cohen L, Larrazet $F$, et al. Preejectional left ventricular wall motion in normal subjects using Doppler tissue imaging and correlation with ejection fraction. Am J Cardiol 1997;80:601-7.

17 Pellerin D, Berdeaux A, Cohen L, et al. Comparison of 2 myocardial velocity gradient assessment methods during dobutamine infusion with Doppler myocardial imaging. J Am Soc Echocardiogr 1999;12:22-31.

18 Gorcsan J, Strum DP, Mandarino WA, et al. Quantitative assessment of alterations in regional left ventricular contractility with color-coded tissue Doppler echocardiography. Comparison with sonomicrometry and pressurevolume relations. Circulation 1997;95:2423-33.

19 Zamorano J, Wallbridge DR, Ge J, et al. Non-invasive assessment of cardiac physiology by tissue Doppler echocardiography. A comparison with invasive haemodynamics. Eur Heart J 1997; 18:350-9.

20 Shan K, Bick RJ, Pointdexter BJ, et al. Relation of tissue Doppler derived myocardial velocities to myocardial structure and beta-adrenergic receptor density in man. J Am Coll Cardiol 2000;36:891-6.

21 Belohlavek M, Bartleson VB, Zobitz ME. Real-time strain rate imaging:validation of peak compression and expansion rates by a tissuemimicking phantom. Echocardigraphy $2001 ; 18: 565-71$.

22 Heimdal A, D'Hooge J, Bijnens B, et al. In vitro validation of in-plane strain rate imaging. A new ultrasound technique for evaluating regional myocardial deformation based on tissue Doppler imaging Echocardiography 1998;15:S40.

23 Urheim S, Edvardsen T, Torp H, et al. Myocardial strain by Doppler echocardiography. Validation of a new method to quantify regional myocardial function. Circulation 2000;102:1158-64.

24 Greenberg NL, Firstenberg MS, Castro PL, et al. Doppler-Derived Myocardial Systolic Strain Rate Is a Strong Index of Left Ventricular Contractility. Circulation 2002;105:99-105.

25 Edvardsen T, Gerber BL, Garot J, et al. Quantitative assessment of intrinsic regional myocardial deformation by Doppler strain rate echocardiography in humans: validation against three-dimensional tagged magnetic resonance imaging. Circulation 2002;106:50-6.

26 Weidemann F, Jamal F, Kowalski M, et al. Can strain rate and strain quantify changes in regional systolic function during dobutamine infusion, $\beta$-blockade, and atrial pacing-implications for quantitative stress echocardiography. J Am Soc Echocardiogr 2002;15:416-24.

27 Voigt JU, Arnold MF, Karlsson M, et al. Assessment of regional longitudinal myocardial strain rate derived from Doppler myocardial imaging indexes in normal and infarcted myocardium. J Am Soc Echocardiogr 2000;13:588-98.

28 Jamal F, Kukulski T, Strotmann J, et al. Quantification of the spectrum of changes in regional myocardial function during acute ischemia in closed chest pigs: an ultrasonic strain rate and strain study. J Am Soc Echocardiogr 2001;14:874-84.

29 Edvardsen T, Skulstad H, Aakhus S, et al. Regional myocardial systolic function during acute myocardial ischemia assessed by strain Doppler echocardiography. J Am Coll Cardiol 2001;37:726-30.

30 Belohlavek M, Pislaru C, Bae RY, et al. Real-time strain rate echocardiographic imaging: temporal and spatial analysis of postsystolic compression in acutely ischemic myocardium. J Am Soc Echocardiogr $2001 ; 14: 360-9$

31 Castro PL, Greenberg NL, Drinko JK, et al. Potential piffalls in strain rate imaging: angle dependency. Biomed Sci Instrum 2000;36:197-202. 
32 Lange $\mathbf{A}$, Walayat $M$, Turnbull $C M$, et al. Assessment of atrial septal defect morphology by transthoracic three dimensional echocardiography using standard grey scale and Doppler myocardial imaging techniques: comparison with magnetic resonance imaging and intraoperative findings. Heart 1997:78:382-9.

33 Alam $M$, Wardelle J, Andersson E, et al. Effects of first myocardial infarction on left ventricular systolic and diastolic function with the use of mitral annular velocity determined by pulsed wave Doppler tissue imaging. J Am Soc Echocardiogr 2000;13:343-52.

34 Gulati VK, Katz WE, Follansbee WP, et al. Mitral annular descent velocity by tissue Doppler echocardiography as an index of global left ventricular function. Am J Cardiol 1996;77:979-84.

35 Feigenbaum H, Zaky A, Nasser WK. Use of ultrasound to measure left ventricular stroke volume. Circulation 1967:38:1092-2099.

36 Rushmer RF, Crystal DK, Wagner C. The functional anatomy of ventricular contraction. Circ Res 1952;1:162-170.

37 Simpson IA. Echocardiographic assessment of the long axis: a simple solution to a complex problem. Heart 1997;78:211-2.

38 Jones CJH, Raposo L, Gibson DG. Functional importance of the longaxis dynamics of the human left ventricle. Br Heart $J$ 1990;63:215-20.

39 Pai RG, Bodenheimer MM, Pai SM, Koss JH, et al. Usefulness of systolic excursion of the mitral anulus as an index of left ventricular systolic function. Am J Cardiol 1991;67:222-4.

40 Yamada H, Oki T, Tabata T, et al. Assessment of left ventricular systolic wall motion velocity with pulsed tissue Doppler imaging: comparison with peak $\mathrm{dP} / \mathrm{dt}$ of the left ventricular pressure curve. J Am Soc Echocardiogr 1998;11:442-9.

41 Nagueh SF, Middleton KJ, Kopelen HA, et al. Doppler tissue imaging: noninvasive technique for evaluation of left ventricular relaxation and estimation of filling pressures. J Am Coll Cardiol 1997;30:1527-33.

42 Vinereanu D, Khokhar A, Tweddel AC, et al. Estimation of global leff ventricular function from the velocity of longitudinal shortening. Echocardigraphy 2002;19:177-85.

43 Gorcsan J, Deswal A, Mankad S, et al. Quantification of the myocardial response to low-dose dobutamine using tissue Doppler echocardiographic measures of velocity and velocity gradient. Am J Cardiol 1998:81:615-23.

44 Yip G, Wang M, Zhang Y, et al. Left ventricular long axis function in diastolic heart failure is reduced in both diastole and systole: time for a redefinition. Heart 2002;87:121-5.

45 Wang M, Yip GW, Wang AY, et al. Peak early diastolic mitral annulus velocity by tissue Doppler imaging adds independent and incremental prognostic value. J Am Coll Cardiol 2003;41:820-6.

46 Meluzin J, Spinarova L, Bakala J, et al. Pulsed Doppler tissue imaging of the velocity of tricuspid annular systolic motion: a new, rapid, and non-invasive method of evaluating right ventricular systolic function. Eur Heart $J$ 2001;22:340-8

47 Ghio S, Rescusani F, Klersy C, et al. Prognostic usefulness of the tricuspid annular plane systolic excursion in patients with congestive heart failure secondary to idiopathic or ischemic dilated cardiomyopathy. Am J Cardiol 2000:85:837-42.

48 Vogel M, Schmidt MR, Kristiansen SB, et al. Validation of myocardial acceleration during isovolumic contraction as a novel noninvasive index of right ventricular contractility. Comparison with ventricular pressure-volume relations in an animal model. Circulation 2002:105:1693-9.

49 Vogel M, Cheung MMH, Li J, et al. Noninvasive assessment of left ventricular force-frequency relationships using tissue Doppler-derived isolvolumic acceleration. Validation in an animal model. Circulation 2003; 107: 1647-52

50 Uematsu M, Nakatani S, Yamagishi $M$, et al. Usefulness of myocardial velocity gradient derived from two-dimensional tissue Doppler imaging as an indicator of regional myocardial contraction independent of translational motion assessed in atrial septal defect. Am J Cardiol 1997;79:237-41.

51 Pellerin D, Berdeaux A, Cohen L, et al. Pre-ejectional left ventricular wall motions studied on conscious dogs using Doppler myocardial imaging. Relationships with indices of left ventricular function. Ultrasound Med Biol 1998;24:1271-83.

52 Alam M, Wardelle J, Andersson E, et al. Characteristics of mitral and tricuspid annular velocities determined by pulsed wave Doppler tissue imaging in healthy subjects. J Am Soc Echocardiogr 1999;12:618-28.

53 Yamada H, Oki T, Mishiro Y, et al. Effect of aging on diastolic left ventricular myocardial velocities measured by pulsed tissue Doppler imaging in healthy subjects. J Am Soc Echocardiogr 1999;12:574-81.

54 Madler CF, Payne N, Wilkenshoff U, et al. Non-invasive diagnosis of coronary artery disease by quantitative stress echocardiography: optimal diagnostic models using off-line tissue Doppler in the MYDISE study. Eur Heart $J$ 2003;24:1584-94.

55 Mishiro $\mathrm{Y}$, Oki T, Yamada H, et al. Evaluation of left ventricular contraction abnormalities in patients with dilated cardiomyopathy with the use of pulsed tissue Doppler imaging. J Am Soc Echocardiogr 1999;12:913-20.

56 Veyrat C, Pellerin D, Larrazet F, et al. Dynamic myocardial velocity changes between phases of the cardiac cycle. Ultrasound in Medicine and Biology (in press).

57 Pai RG, Gill KS. Amplitudes, durations, and timings of apically directed left ventricular myocardial velocities: I. Their normal pattern and coupling to ventricular filling and eiection. I Am Soc Echocardiogr 1998:11:105-11.

58 Galiuto L, Ignone G, DeMaria AN. Contraction and relaxation velocities of the normal left ventricle using pulsed-wave tissue Doppler echocardiography. Am J Cardiol 1998;81:609-14.

59 Garcia MJ, Rodriguez L, Ares M, et al. Myocardial wall velocity assessment by pulsed Doppler tissue imaging: characteristic findings in normal subjects. Am Heart J 1996;132:648-56.
60 Gorcsan J, Gulati VK, Mandarino WA, et al. Color-coded measures of myocardial velocity throughout the cardiac cycle by tissue Doppler imaging to quantify regional left ventricular function. Am Heart $J$ 1996;131:1203-13.

61 Pai RG, Gill KS. Amplitudes, durations, and timings of apically directed left ventricular myocardial velocities: II. Systolic and diastolic asynchrony in patients with left ventricular hypertrophy. J Am Soc Echocardiogr 1998;11:112-8.

62 Pellerin D, Cohen L, Larrazet F, et al. New insights into septal anterior wall motion velocities at end-systole in normal and hypertrophied left ventricles. Eur J Echocardiogr 2003;4:108-18.

63 Weidemann F, Eyskens B, Jamal F, et al. Quantification of regional left and right ventricular radial and longitudinal function in healthy children using ultrasound-based strain rate and strain imaging. J Am Soc Echocardiogr 2002;15:20-8.

64 Isaaz K, Munoz del Romeral L, Lee E, et al. Quantitation of the motion of the cardiac base in normal subjects by Doppler echocardiography. J Am Soc Echocardiogr 1993;6:166-76.

65 Alam M, Hogherd C, Thorstrand C, et al. Haemodynamic significance of the atrioventricular plane displacements in patients with coronary artery disease. Eur Heart J 1992;13:194-200.

66 Derumeaux G, Ovize M, Loufoua J, et al. Doppler tissue imaging quantitates regional wall motion during myocardial ischemia and reperfusion. Circulation 1998;97:1970-7.

67 Kukulski T, Jamal F, D'Hooge J, et al. Acute changes in systolic and diastolic events during clinical coronary angioplasty: a comparison of regional velocity, strain rate, and strain measurement. J Am Soc Echocardiogr 2002;15:1-12.

68 Jamal F, Kukulski T, D'Hooge J, et al. Abnormal postysystolic thickening in autely ischemic myocardium during coronary angioplasty: a velocity, strain, and strain rate Doppler myocardial imaging study. J Am Soc Echocardiogr 1999;12:994-6.

69 Jamal F, Strotmann J, Weidemann F, et al. Noninvasive quantification of the contractile reserve of stunned myocardium by ultrasonic strain rate and strain. Circulation 2001;104:1059-65.

70 Pislaru C, Belohlavek M, Bae RY, et al. Regional asynchrony during acute myocardial ischemia quantified by ultrasound strain rate imaging. J Am Coll Cardiol 2001:37:1141-8.

71 Voigt JU, Lindenmeier G, Exner B, et al. Incidence and characteristics of segmental postsystolic longitudinal shortening in normal, acutely ischemic, and scarred myocardium. J Am Soc Echocardiogr 2003;16:415-23.

72 Derumeaux GA, Loufoua J, Pontier G, et al. Tissue Doppler imaging differentiates transmural from nontransmural acute myocardial infarction after reperfusion therapy. Circulation 2001;103:589-96.

73 Armstrong G, Pasquet A, Fukamachi K, et al. Use of peak systolic strain as an index of regional left ventricular function: comparison with tissue Doppler velocity during dobutamine stress and myocardial ischemia. J Am Soc Echocardiogr 2000;13:731-7.

74 Hatle L, Sutherland GR. Regional myocardial function-a new approach. Eur Heart J 2000;21:1337-57.

75 Garot J, Derumeaux GA, Monin JL, et al. Quantitative systolic and diastolic transmyocardial velocity gradients assessed by M-mode colour Doppler tissue imaging as reliable indicators of regional left ventricular function after acute myocardial infarction. Eur Heart $J$ 1999;20:593-603.

76 Palmes PP, Masuyama T, Yamamoto K, et al. Myocardial longitudinal motion by tissue velocity imaging in the evaluation of patients with myocardial infarction. J Am Soc Echocardiogr 2000;13:818-26.

77 Garcia-Fernandez MA, Azevedo J, Moreno M, et al. Regional diastolic function in ischaemic heart disease using pulsed wave Doppler tissue imaging. Eur Heart J 1999:20:496-505.

78 Pellerin D, Brecker SJ. A step further in inter-institutional agreement in interpretation of dobutamine stress echocardiograms. Eur Heart $J$ 2002;23:768-71.

79 Pasquet A, Armstrong G, Rimmerman C, et al. Correlation of myocardial Doppler velocity response to exercise with independent evidence of myocardial ischemia by dual-isotope single-photon emission computed tomography. Am J Cardiol 2000;85:536-42.

80 Pasquet A, Armstrong G, Beachler L, et al. Use of segmental tissue Doppler velocity to quantitate exercise echocardiography. J Am Soc Echocardiogr 1999;12:901-12

81 Cain P, Baglin T, Case C, et al. Application of tissue Doppler to interpretation of dobutamine echocardiography and comparison with quantitative coronary angiography. Am J Cardiol 2001;87:525-31

82 Tsutsui $H$, Uematsu $M$, Shimizu $H$, et al. Comparative usefulness of myocardial velocity gradient in detecting ischemic myocardium by a dobutamine challenge. J Am Coll Cardiol 1998;31:89-93.

83 Voigt JU, Exner B, Schmiedehausen K, et al. Strain-rate imaging during dobutamine stress echocardiography provides objective evidence of inducible ischemia. Circulation 2003;107:2120-6.

84 Abraham TP, Belohlavek M, Thompson HL, et al. Time to onset of regional relaxation: feasibility, variability and utility of a novel index of regional myocardial function by strain rate imaging. I Am Coll Cardiol 2002;39:1531-7.

85 Altinmakas S, Dagdeviren B, Uyan C, et al. Prediction of viability by pulsedwave Doppler tissue sampling of asynergic myocardium during low-dose dobutamine challenge. Int $J$ cardiol 2000;74:107-13.

86 Rambaldi R, Poldermans D, Bax JJ, et al. Doppler tissue velocity sampling improves diagnostic accuracy during dobutamine stress echocardiography for the assessment of viable myocardium in patients with severe left ventricular dysfunction. Eur Heart J 2000;21:1091-8. 
87 Larrazet F, Pellerin D, Daou D, et al. Concordance between dobutamine Doppler tissue imaging echocardiography and rest-reinjection Tl-201 tomography in myocardial hibernation. Heart 1999;82:432-7.

88 Nishino M, Tanouchi J, Tanaka K, et al. Dobutamine stress echocardiography at $7.5 \mathrm{mg} / \mathrm{kg} / \mathrm{min}$ using color tissue Doppler imaging $M$ mode safely predicts reversible dysfunction early after reperfusion in patients with acute myocardial infarction. Am J Cardiol 1999;83:340-4.

89 Larrazet F, Pellerin D, Prigent A, et al. Quantitative analysis of hibernating myocardium by dobutamine tissue Doppler echocardiography. Am J Cardiol 2001:88:418-22.

90 Hoffmann R, Altiok E, Nowak B, et al. Strain rate measurement by Doppler echocardiography allows improved assessment of myocardial viability in patients with depressed left ventricular function. J Am Coll Cardiol 2002;39:443-9.

91 Nagueh SF, Kopelen HA, Lim DS, et al. Tissue Doppler imaging consistently detects myocardial contraction and relaxation abnormalities, irrespective of cardiac hypertrophy, in a transgenic rabbit model of human hypertrophic cardiomyopathy. Circulation 2000;102:1346-50.

92 Nagueh SF, Bachinski LL, Meyer D, et al. Tissue Doppler imaging consistently detects myocardial abnormalities in patients with hypertrophic cardiomyopathy and provides a novel means for an early diagnosis before and independently of hypertrophy. Circulation 2001;104:128-30.

93 Derumeaux GA, Mulder P, Richard V, et al. Tissue Doppler imaging differentiates physiological from pathological pressure-overload left ventricular hypertrophy in rats. Circulation 2002;105:1602-8.

94 Vinereanu D, Florescu N, Sculthorpe N, et al. Differentiation between pathologic and physiologic left ventricular hypertrophy by tissue Doppler assessment of long-axis function in patients with hypertrophic cardiomyopathy or systemic hypertension and in athletes. Am J Cardiol 2001;88:53-8.

95 Garcia MJ, Rodriguez L, Ares M, et al. Differentiation of constrictive pericarditis from restrictive cardiomyopathy: assessment of left ventricular diastolic velocities in longitudinal axis by Doppler tissue imaging. J Am Coll Cardiol 1996;27:108-14.
96 Palka P, Lange A, Donnelly JE, et al. Differentiation between restrictive cardiomyopathy and constrictive pericarditis by early diastolic Doppler myocardial velocity gradient at the posterior wall. Circulation 2000; 102:655-62.

97 Koyama J, Ray-Sequin PA, Falk RH. Longitudinal myocardial function assessed by tissue velocity, strain, and strain rate tissue Doppler echocardiography in patients with AL (primary) cardiac amyloidosis. Circulation 2003;107:2446-52.

98 Pieroni M, Chimenti C, Ricci R, et al. Early detection of Fabry cardiomyopathy by tissue Doppler imaging. Circulation 2003;107:1978-84.

99 Dutka DP, Donnelly JE, Palka P, et al. Echocardiographic characterization of cardiomyopathy in Friedreich's ataxia with tissue Doppler echocardiographically derived myocardial velocity gradients. Circulation 2000; 102:1276-82.

100 Weidemann F, Eyskens B, Mertens L, et al. Quantification of regional right and left ventricular function by ultrasonic strain rate and strain indexes in Friedreich's ataxia. Am J Cardiol 2003;91:622-6.

101 Yu CM, Lin H, Zhang Q, et al. High prevalence of left ventricular systolic and diastolic asynchrony in patients with congestive heart failure and normal QRS duration. Heart 2003;89:54-60.

102 Yu CM, Chau E, Sanderson JE, et al. Tissue Doppler echocardiographic evidence of reverse remodeling and improved synchronicity by simultaneously delaying regional contraction after biventricular pacing therapy in heart failure. Circulation 2002;105:438-45.

103 Ansalone G, Giannantoni P, Ricci R, et al. Doppler myocardial imaging to evaluate the effectiveness of pacing sites in patients receiving biventricular pacing. J Am Coll Cardiol 2002;39:489-99.

104 Cazeau S, Gras D, Lazarus A, et al. Multisite stimulation for correction of cardiac asynchrony. Heart 2000;84:579-81

105 Linde C, Leclercq C, Rex S, et al. Long-term benefits of biventricular pacing in congestive heart failure: results from the multisite stimulation in cardiomyopathy (MUSTIC) study. J Am Coll Cardiol 2002;40:111-8. 


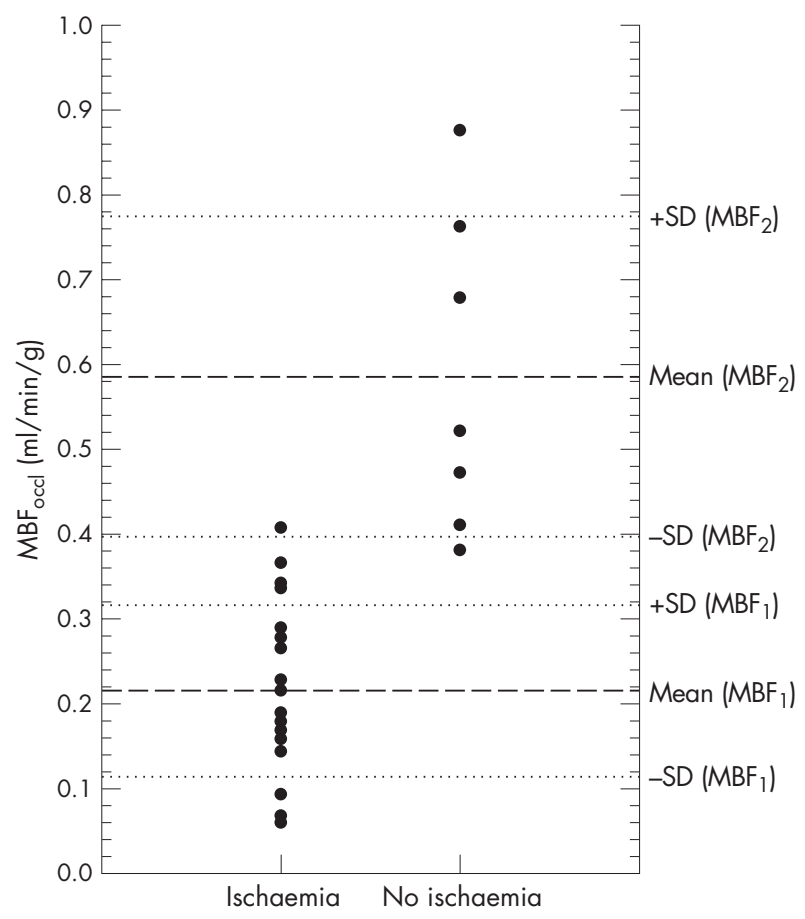

Figure 1 Residual myocardial blood flow $\left(\mathrm{MBF}_{\text {ocl }}\right)$ during angioplasty in patients with (group 1) and without (group 2) ischaemia; dashed and dotted lines indicate mean $\pm 1 S D M B F_{\text {ocd }}$ of the respective groups.

Regarding the definition of ischaemia, electrocardiogram changes as a surrogate end point are well established during angioplasty. ${ }^{5}$ Metabolic studies such as coronary blood sampling or metabolic imaging are not feasible in this setting. Regional wall motion analysis was unreliable in most cases, as we had to use atypical views showing only the target territory and adjacent segments with the patients in supine position.

Ultrasound contrast agents are pure intravascular tracers and perfusion measurements by MCE do not interfere with metabolic dysfunction that accrues early in ischaemia Regarding the clinical implications of the presented results, we therefore suggest that MBF measurements by MCE can be used for myocardial viability studies without metabolic assessment as required by positron electron tomography.

\section{Authors' affiliations}

R Vogel, A Indermühle, C Seiler, Department of Cardiology, University Hospital Bern, Bern, Switzerland

Funding: This work was supported by grants from the Swiss National Science Foundation (number 3200B0-100065) and the Swiss Heart Foundation.

Competing interests: None.

Correspondence to: Professor Christian Seiler, Department of Cardiology, University Hospital Bern, CH-3010 Bern, Switzerland; christian.seiler@insel.ch

Accepted 9 May 2006

\section{REFERENCES}

1 Nesto RW, Kowalchuk GJ. The ischemic cascade: temporal sequence of hemodynamic, electrocardiographic and symptomatic expression of ischemia. Am J Cardiol 1978:57:23C-30C.

2 Vogel R, Indermühle A, Reinhardt J, et al. The quantification of absolute myocardial perfusion in humans using contrast echocardiography: algorithm and validation. J Am Coll Cardiol 2005; 45:754-62.

3 Chareonthaitawee $\mathbf{P}$, Kaufmann PA, Rimoldi $\mathrm{O}$, et al. Heterogeneity of resting and hyperemic myocardial blood flow in healthy humans. Cardiovasc Res 2001;50:151-61

4 Lee CW, Park SW, Cho GY, et al. Pressure-derived fractional collateral blood flow: a primary determinant of left ventricular recovery after reperfused acute myocardial infarction. J Am Coll Cardiol 2000;35:949-55.

5 Seiler C, Fleisch M, Garachemani A, et al. Coronary collateral quantitation in patients with coronary artery disease using intravascular flow velocity or pressure measurements. J Am Coll Cardiol 1998;32:1272-9.

\section{WEB TOP 10}

www.heartjnl.com

These articles scored the most hits on Heart's website during October 2006

1 JBS 2: Joint British Societies' guidelines on prevention of cardiovascular disease in clinical practice

December 2005;91(suppl V):1-52. (Supplement)

2 Heart failure: statins for all?

AF Leite-Moreira, $P$ Castro-Chaves

November 2006;92:1537-8. (Editorial)

3 Treating patients with ventricular ectopic beats

$\mathrm{GANg}$

November 2006;92:1707-12. (Education in Heart)

4 Drug induced QT prolongation and torsades de pointes

YG Yap, AJ Camm

November 2003;89:1363-72. (Education in Heart)

5 Epidemiology and antibiotic treatment of infective endocarditis: an update

B Hoen

November 2003;89:1694-700. (Education in Heart)

6 The changing face of infective endocarditis

$E$ Cecchi, $M$ Imazio, $R$ Trinchero

October 2006;92:1365-6 (Editorial)

7 Management of dyslipidaemias

$P$ Paramsothy, $R$ Knopp

October 2006;92:1529-34. (Education in Heart)

8 Pregnancy in heart disease

SA Thorne

April 2004;90:450-6. (Education in Heart)

9 Tissue Doppler, strain, and strain rate echocardiography for the assessment of left and right systolic ventricular function

$D$ Pellerin, $R$ Sharma, P Elliott, C Veyrat

November 2003;89(suppl III):iii9-17. (Supplement)

10 Management of hypertension before, during, and after pregnancy

PR James, C Nelson-Piercy

December 2004;90:1499-504. (Education in Heart)

Visit the Heart website for hyperlinks to these articles, by clicking on "Top 10 papers"

www.heartinl.com 